\title{
Problems and Strategies of Cross-border Mergersand Acquisitions for Chinese Enterprises
}

\author{
Z.M. Li, J.J. Jiang
}

School of Management, Guangdong University of Technology, CHINA

\begin{abstract}
With the accelerated process of economic globalization and China's growing enterprises, Chinese enterprises are starting to treat cross-border mergers and acquisitions as a new strategy for foreign direct investment and the development of international markets. However, while the rapid development of cross-border mergers and acquisitions, many Chinese enterprises encountered lots of setbacks and failures, which are closely related to the lack of experience of the cross-border mergers and acquisitions. This paper is intended to analyze cross-border mergers and acquisitions, finds out the problems for the Chinese companies in the process of cross-border $\mathrm{M} \& \mathrm{~A}$, and finally proposes some recommendations accordingly.
\end{abstract}

Key Words: Economic globalization, transnational mergers and acquisitions, multinationals, Chinese enterprises

\section{INTRODUCTION}

Under the background of economic globalization, enterprise internationalization is sweeping the globe. In order to strengthen its international competitive position and implement global business strategy, multinationals have launched a large-scale, farreaching cross-border $\mathrm{M} \& \mathrm{~A}$ wave in the whole world. Through cross-border mergers and acquisitions, multinational companies can bypass the host country trade barriers and investment restrictions, quickly enter and dominate their markets; can be integrated into the global resources, access to natural resources necessary for the development, technology, brands, and bring the expansion of enterprise scale achieving economies of scale; can sustain profitable growth, diversify its business portfolio and re-positioning; meet the development needs of the capital markets and so on. Cross-border mergers and acquisitions have become the main form of TNCs foreign investment, the implementation of global development strategies.

With the strategy of "going out", more and more Chinese enterprises go abroad, aiming at the global market. With the accelerated process of economic globalization and China's growing enterprises, Chinese enterprises are starting to treat cross-border mergers and acquisitions as a novel strategy for foreign direct investment and the development of international markets.The cross-border mergers and acquisitions for Chinese enterprises began in the 1980s. Compared with the United States' and European countries', it's a very 
short time, but growing rapidly. The amount of cross-border M \& A transactions grows from 2002's \$ 200 million to more than 300 billion dollars now.Currently,cross-border mergers and acquisitions play a huge role in China's foreign investment.

However, while the rapid development of cross-border mergers and acquisitions, many Chinese enterprises encountered lots of setbacks and failures, which are closely related to the lack of experience of the cross-border mergers and acquisitions. So, why is the failure rate of cross-border mergers and acquisitions so high? This paper is intended to analyze cross-border mergers and acquisitions, finds out the problems for the Chinese companies in the process of cross-border $\mathrm{M} \& \mathrm{~A}$, and finally proposes some recommendations accordingly.

\section{The Problems of Chinese Enterprises in Cross-Border M \& A}

Compared with developed countries, the problems of cross-border mergers and acquisitions for Chinese enterprises are mainly: the strategy of $M$ \& A; the selection and valuation of target enterprises; the acquisition financing and payment; the integration after $\mathrm{M} \& \mathrm{~A}$.

\section{The Strategy of $M \mathcal{E} A$}

Currently, there is a misunderstanding of cross-border M \& A for many Chinese enterprises, which did not realize that it's just a choice to achieve international business in a certain stage and a specific market environment, also did not recognize that the cross-border M \& A are not the end of $\mathrm{M} \& \mathrm{~A}$, but with the aim of improving the core competitiveness of enterprises. Many Chinese enterprises just blindly follow the trend, which can cause the conflict of longterm business development strategy and cross-border M \& A strategy.

\section{The Selection and Valuation of Target Enterprises}

It's very difficult for the Chinese enterprises to conduct a reasonable valuation of the target company, what's worse, with some objective or subjective reasons; it is prone to improper projections.

Chinese enterprises in the difficult process of cross-border mergers and acquisitions reasonable valuation of the target company, plus some objective or subjective reasons, it is prone to improper projections. If the forecast is too high, it can result in the unnecessary costs and then financial distress. If the forecast is too low, it may directly lead to the failure of cross-border M \& A, and then the waste of transaction costs.

\section{The Acquisition Financing and Payment}

In China, due to the imperfect development of capital markets, cross-border mergers and acquisitions are mainly paid in cash. The cash payment of cross-border mergers and acquisitions is very strict, which makes many Chinese enterprises encounter setbacks. A large outflow of cash makes companies reduce capital mobility, which can increase the financial risk for the enterprises; The cash payment faces enormous interest and exchange rate risks, and compared with other methods of payment, the cash payment cannot enjoy the tax saving benefits. Furthermore, the restrictions on bank loans, the difficulties of stocks, bonds issued in China also result in difficulties in financing enterprises.

\section{The Integration after $M \mathcal{E} A$}

After $M$ \& A, two sides are just combined on the surface. Not integrated enterprises will be in a state of confusion that has some contradictions of each other. Through the effective integration, cross-border $\mathrm{M} \& \mathrm{~A}$ can reduce the presence of contradictions and conflicts, improve the synergies, and thereby enhance the core competitiveness of enterprises. 


\title{
Some Advices for Chinese Enterprises in Cross-Border M \& A
}

\author{
Toclear the purpose and develop the scientific and rational strategy for the $M \mathcal{E} A$
}

\section{Toclear the purpose of the $M$ \& $A$}

Cross-border M \& A should be a part of business development strategy, rather than a corporate whim, that is, enterprises must have a clear purpose of Cross-border M \& A. Before determining the purpose of Cross-border $M \& A$, enterprises must have a clear understanding and knowledge to the own development strategy, whether the enterprises really need the mergers and acquisitions business at this stage, whether it is the best way of foreign investment, rather than out of opportunism psychological or impulse, etc.

\section{Strengthen research assessment and develop a scientific and rational strategy for cross-border $\mathbf{M} \& \mathbf{A}$}

In the case of explicit purpose of cross-border $M \& A$, from the internationalization development strategy of enterprises, the enterprises should clear the purpose of crossborder M \& A to select the mergers and acquisitions business, which are consistent with their own enterprises. Before the implementation of cross-border M \& A, enterprises must conduct their own investigation to get a comprehensive assessment for the target company. On the one hand, the enterprises must have an assessment for their own strength and scale to detect and compensate for their deficiencies, including capital cases, financial condition and manpower to explicit their own choice of target companies, financing capability, the ability to integrate cross-border mergers and acquisitions, etc. On the other hand, the enterprises must have an assessment for the target company, also including the business situation of enterprises, financial condition, human resources, technology, market share, and so on. Meanwhile, the enterprises must have a comparison to the external influences, including the country's economic, political, legal, cultural and other to understand the difficulty of cross-border M \& A.

\section{ToSelected the Target Companies Carefully, and Set a Reasonable Price}

The selection and price of target enterprises directly determine the success or failure of cross-border M \& A. Choosing a good target company and set a reasonable valuation is very important for enterprises.

\section{To make full use of the internationally renowned agency}

Due to the lack of experience of cross-border M \& A, Chinese enterprises should make extensive use of the service provided by internationally renowned investment banks, accounting firms, law firms, etc. Internationally renowned agency can accurately grasp the target company's information and reduce the risk of information asymmetry brings enterprise valuation; the international agencies have professional talents, strong independence, which can accurately judge the financial situation and operating conditions for the enterprises; the international agencies can provide advices and guidance to cross-border $\mathrm{M} \& \mathrm{~A}$, especially in the phase of valuation and integration, thereby reducing unnecessary losses and lower acquisition costs. But it cannot completely rely on the agencies. In order to facilitate the completion of cross-border M \& A, they may hide some of the risks involved. In a word, the enterprises should participate in the whole process of cross-border $\mathrm{M} \& \mathrm{~A}$, and enhance understanding of their own enterprises to facilitate post-merger integration and management. 


\section{Improve business valuation}

A variety of assessment methods have its scope, and the enterprises should use different assessment methods to the target enterprises. Chinese enterprises should be based on the goal of cross-border M \& A, the situation of the target enterprises, and the mastery extent of information to select the appropriate business valuation methods and models.

\section{ToBroaden the Financing Channels, and Diversify Financing Payment}

The support of substantial capital is in needto cross-border M \& A. And in developed countries, abundant financing channels provide a strong capital protection for crossborder M \& A. Compared with developed countries', financing channels for Chinese enterprises are very narrow and single. Single cash payment and bank loans or limited domestic capital market hindered the development of cross-border mergers and acquisitions in China to some extent. To alleviate the pressure of the Chinese enterprises in cross-border $\mathrm{M} \& \mathrm{~A}$ and reduce the financial risks brought by single financing mode of payment, Chinese enterprises can take the following measures:

\section{To improve the way of payment, encourage enterprise equity of listed companies to pay}

Equity to pay for foreign listed enterprises in cross-border M \& $A$ is the main mode of payment, which is what Chinese enterprises lack. Pay equity is widely used in between the listed companies, listed companies and non-listed companies. It can reduce a large amount of cash, and cash liquidity risk, and it also can enjoy the tax benefits. In addition, the most important thing is that it makes both sides of $\mathrm{M} \& \mathrm{~A}$ share the risk of the valuation.

\section{To broad the financing channels}

Because China's capital market development is imperfect, the issuance of stocks or the examination and approval of bonds is very strict and complicated, which makes financing channel narrow in China. Chinese enterprises should widely expand financing channels, and reduce the financial risks for the solo financing channel. First, Chinese enterprises should strengthen the close contact with domestic banks and other financial institutions, and maintain good fixed capital source through mutual equity participation or agreement with banks. Second, they actively expand overseas financing channels. Perfect capital market in the developed countries can make the overseas listed companies conduct M \& A by equity financing, debt financing, or "back-door listing" overseas financing. Finally, they should use financial tools flexibly, and reduce the risk of exchange rate and interest rate. When carry out financing or payment, Chinese enterprises can choose an appropriate monetary or several currencies to expand funding sources and reduce the exchange rate risk, also can use financial instruments to lock exchange rate losses.

\section{To Attach Great Importance to the Integration after cross-border $M \mathcal{E} A$}

The integration after $\mathrm{M} \& \mathrm{~A}$ is the most critical step in cross-border $\mathrm{M} \& \mathrm{~A}$.If the value is insufficient, even if finished, without good integration to achieve synergies, it will eventually lead to the failure of cross-border $M$ \& A. Many Chinese companies that didn't pay sufficient attention to the integration after $M \& A$ paid a great price. For the integration after $\mathrm{M} \& \mathrm{~A}$, Chinese companies should allow the following aspects: 


\section{Management integration strategy}

Integration management goal is to achieve production integration, financial integration, integration management, sales integration of integrated management, to reduce the cost, create more profits for the enterprise.

\section{Human resources integration strategy}

The competition between the enterprises in the final analysis is the talent competition. Chinese enterprises should on the basis of investigation and analysis, formulate scientific and reasonable human resource integration strategy, stability of the target enterprise talent. Human resources integration has the following three suggestions: strengthen the understanding of the host system and target enterprise; stabilize the target enterprise talent; strengthen exchanges and communication.

\section{Enterprise culture integration strategy}

Enterprise culture integration, as the most basic part of the merger integration process, directly affects and decides the success or failure of the whole process of consolidation. Chinese enterprises must strengthen the attention to the cultural integration, develop scientific cultural integration strategy, through integration, and reduce the huge difference of culture and the impact of promoting the smooth completion of the merger integration. First of all, enterprises should deal with evaluation analysis for the culture of the target enterprise, identifythecultural differences. Second, they should strengthen the communication with the target enterprise employees and exchanges. Thirdly, through cultural training, they can promote the integration of culture. Finally, they should pay attention to the speed of integration.

In the process of cross-border $M \& A$ integration, enterprises must pay attention to the operation and management integration, integration of human resources and enterprise cultural integration of coordination, not only focus on one side, but ignore other aspects. At the same time, they also should pay attention to the communication and exchanges, because good communication and exchange is a key to the success of $\mathrm{M} \& \mathrm{~A}$ integration.

\section{Conclusions}

Since the 21st century, with the further development of economic globalization, cross-border M \& A has become a remarkable phenomenon in world economic activity. So, the raise of success rate of $\mathrm{M} \& \mathrm{~A}$ has become the most important thing for those who want to expand power and influence of enterprise by cross-border $M$ \& A. This paper introduces some of the major problems in Chinese enterprises in cross-border $M$ \& A, and then puts forward relevant advice to solve these problems, which hope that through these studies, Chinese enterprises can improve the success rate for cross-border $\mathrm{M} \& \mathrm{~A}$ in stage of the whole world.

\section{REFERENCES}

Jun Pu. The Risk and Control Strategies in cross-Border Mergers and Acquisitions for Chinese Enterprises [J].Accounting Newsletter, 2008, 10:114-117.

Ling Peng. The Integrate Risk and Prevention Strategies of cross-Border Mergers and Acquisitions for Chinese Enterprises [J]. The Journal of Jiaying College, 2007(5):121-125.

Qun Yang. Target Companies' Choice Analysis in Cross-Border Mergers and Acquisitions for Chinese Enterprises [J]. Modern Business, 2008(3):98-99.

Robert J Borghese, Borgese. M\&A form planning to integration [J]. New York: McGraw-Hill, 2011 
Xiao Liu. Problems Research in Cross-Border Mergers and Acquisitions for Chinese Enterprises [D]. Beijing: Beijing Forestry University,2009.

Yunfeng Liao. Overseas Mergers and Acquisitions for Chinese Enterprises [M]. Beijing: China Economic Press, 2006. 